\title{
Classification of compressed breast shapes for the design of equalization filters in x-ray mammography
}

\author{
Mitchell M. Goodsitt, ${ }^{\text {a) }}$ Heang-Ping Chan, Bob Liu, ${ }^{\text {b) }}$ Shankar V. Guru, ${ }^{\mathrm{c})}$ A. Ray Morton, ${ }^{\text {d) }}$ \\ Shyam Keshavmurthy, and Nick Petrick \\ Department of Radiology, University of Michigan Hospital, Ann Arbor, Michigan 48109
}

(Received 28 May 1997; accepted for publication 17 March 1998)

\begin{abstract}
We are developing an external filter method for equalizing the x-ray exposure in mammography. Each filter is specially designed to match the shape of the compressed breast border and to preferentially attenuate the x-ray beam in the peripheral region of the breast. To be practical, this method should require the use of only a limited number of custom built filters. It is hypothesized that this would be possible if compressed breasts can be classified into a finite number of shapes. A study was performed to determine the number of shapes. Based on the parabolic appearances of the outer borders of compressed breasts in mammograms, the borders were fit with the polynomial equations $y=a x^{2}+b x^{3}$ and $y=a x^{2}+b x^{3}+c x^{4}$. The goodness-of-fit of these equations was compared. The $a, b$ and $a, b, c$ coefficients were employed in a K-Means clustering procedure to classify 470 CC-view and 484 MLO-view borders into 2-10 clusters. The mean coefficients of the borders within a given cluster defined the "filter" shape, and the individual borders were translated and rotated to best match that filter shape. The average rms differences between the individual borders and the "filter" were computed as were the standard deviations of those differences. The optimally shifted and rotated borders were refit with the above polynomial equations, and plotted for visual evaluation of clustering success. Both polynomial fits were adequate with rms errors of about $2 \mathrm{~mm}$ for the 2-coefficient equation, and about $1 \mathrm{~mm}$ for the 3-coefficient equation. Although the fits to the original borders were superior for the 3-coefficient equation, the matches to the "filter" borders determined by clustering were not significantly improved. A variety of modified clustering methods were developed and utilized, but none produced major improvements in clustering. Results indicate that 3 or 4 filter shapes may be adequate for each mammographic projection (CCand MLO-view). To account for the wide variations in exposures observed at the peripheral regions of breasts classified to be of a particular shape, it may be necessary to employ different filters for thin, medium and thick breasts. Even with this added requirement, it should be possible to use a small number of filters as desired. (c) 1998 American Association of Physicists in Medicine. [S0094-2405(98)00106-0]
\end{abstract}

Key words: mammography, equalization, classification, filtration

\section{INTRODUCTION}

Mammographic abnormalities related to early breast cancers include clustered microcalcifications, spiculated and irregular masses, areas of parenchymal distortion, and skin thickening. ${ }^{1,2}$ These abnormalities are often subtle and low contrast. Therefore, low-energy radiation and high-contrast screen/film systems are recommended for mammographic imaging in order to increase the contrast between the lesion and the background tissue. Despite the use of vigorous compression during examinations, ${ }^{3}$ the low-energy x-ray beam results in a wide dynamic range (the ratio of the maximum to the minimum $x$-ray exposure at the detector) for the radiation penetrating the breast. This range can be greater than $100 .{ }^{4}$ On the other hand, high-contrast film provides a narrow latitude which is about 10 for a typical mammographic system. ${ }^{5,6}$ As a result, thick and glandular regions of the breast are often imaged at the toe of the sigmoid-shaped sensitometric curve of the screen/film system; whereas thin peripheral regions are imaged at the shoulder. The contrast and signal-to-noise ratio (SNR) of mammographic features are greatly reduced in these regions due to decreased film gradient. The contrast sensitivity of the human visual system also drops rapidly as the film density increases. ${ }^{7-9}$ Kopans $^{10}$ found that $70 \%$ of breast cancers in women with dense breasts are in the periphery of the mammary parenchyma adjacent to the subcutaneous fat or retromammary fat. The poor image quality in the peripheral region thus imposes a serious limitation on the sensitivity of cancer detection in breasts with dense fibroglandular tissue.

A variety of exposure equalization methods have been proposed to improve mammographic imaging. In one, either a water bag $^{11-13}$ or a solid, elastic, unit density $\mathrm{x}$-ray attenuator ${ }^{14}$ is placed between the breast and the compression paddle to make the total breast thickness uniform all the way out to the periphery. This gap-filling method has the advantage of being patient specific. However, it can be difficult to implement, especially for oblique views. Another, more sophisticated method involves scanning of the breast 
with either single or multiple $\mathrm{x}$-ray beams that are intensity modulated based on $\mathrm{x}$-ray transmission signals obtained from single or multiple detectors. ${ }^{15,16}$ Such a method can equalize the exposure throughout the breast rather than just at the periphery. However, the method is complex and requires much greater heat loading of the $\mathrm{x}$-ray tube than conventional mammography. Recently, a rotary scanning equalization method has been developed that reduces, but does not eliminate the heat loading and complexity issues. ${ }^{17}$

We have proposed a practical and cost-effective exposure equalization method for reducing the dynamic range of the mammograms. The method employs a set of x-ray beam intensity shaping filters that are positioned near the collimator of the mammography system. Each filter is designed to match the shape of the compressed breast border and to preferentially reduce the exposure to the detector in the peripheral region of the breast. It is our hypothesis that compressed breasts can be classified into a finite number of shapes, and therefore only a finite number of filters will be needed. In this paper, we report on the results of a study we conducted to determine the validity of our hypothesis.

\section{METHODS}

\section{A. Border detection and modeling}

1004 clinical mammograms including both craniocaudal (CC) and mediolateral oblique (MLO) views were digitized with a DBA Systems, Inc. (Melbourne, Florida) model ImageClear M2100 film digitizer. This system has 21 micron resolution, which is much finer than is required for our application. We operated the digitizer in a mode whereby two of every three pixels is skipped, yielding an effective resolution of 63 microns. The resolution was further reduced to 1 $\mathrm{mm}$ by averaging the pixel values in $1 \mathrm{~mm}$ areas. The light transmission through the films was digitized in 16-bit linear format, and these values were later converted to 12-bit logarithmic format to yield a fairly linear relationship between film optical density and digitized value.

An automated border tracing algorithm was applied to the digitized images. ${ }^{18}$ Acceptable borders were obtained in $95 \%$ of the mammograms (954 of the 1004), which formed the data set used in our study. The $5 \%$ of the mammograms that were excluded exhibited problems such as: (1) a substantial portion of the breast edge extended outside the imaging area of the film; (2) a significant portion of the breast edge was obscured by a patient label; and (3) numerous artifacts (e.g., streaks) were present at the breast periphery caused by the film digitizer. In a separate study, we found the automated border trace routine to be accurate. Comparing the difference between hand-traced and automatically detected borders in a random sample of images, we computed an average rootmean-square difference of $1.4 \mathrm{~mm}$ (1.4 pixels). ${ }^{19}$ An example of the manually traced and automatically detected borders is shown in Fig. 1.

A total of 470 CC-view and 484 MLO-view automatically traced borders were analyzed in the present study. In reviewing these borders, we observed that the shapes appear to be well characterized by either symmetric or asymmetric poly-

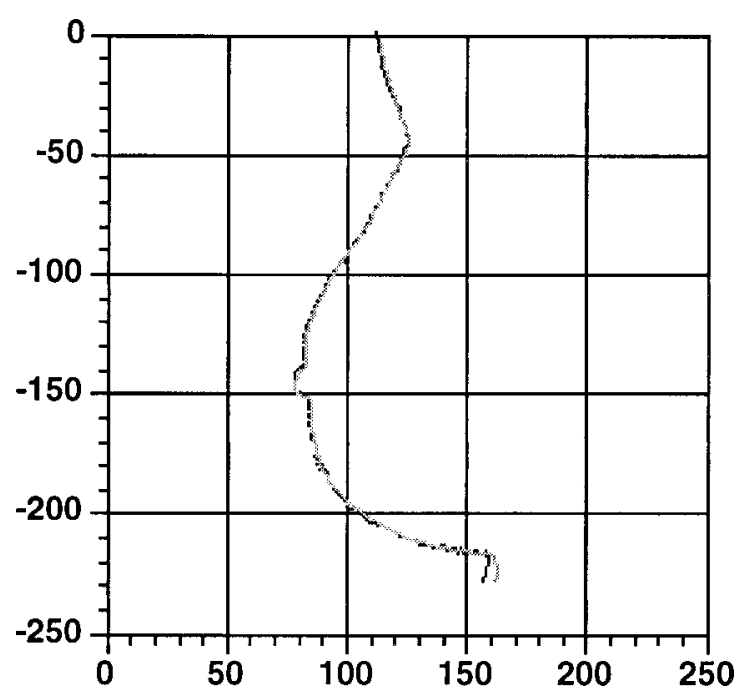

FIG. 1. Example of automatic versus hand-traced compressed breast borders. The hand-traced border is indicated by the lighter gray curve.

nomials. Therefore, we decided to model the borders with the polynomial equations $y=a x^{2}+b x^{3}$ and $y=a x^{2}+b x^{3}$ $+c x^{4}$. These equations have the advantage of producing only two $(a, b)$ or three $(a, b$, and $c)$ coefficients which can be used in cluster analysis to classify the border shapes.

\section{B. The border fitting procedure}

The fitting procedure involves either translating and rotating the borders about the $x$ - and $y$-axes or, equivalently, translating and rotating the axes. We wrote custom software to accomplish this task. The method is described below.

First, small irregularities are removed from the borders by applying run-length averaging (run-length employed $=15$ ).

Next, an initial best estimate of the axis positions is made. The approach that was utilized is illustrated in Fig. 2. In brief, it determines the $y^{\prime}$-axis by least-square fitting a line

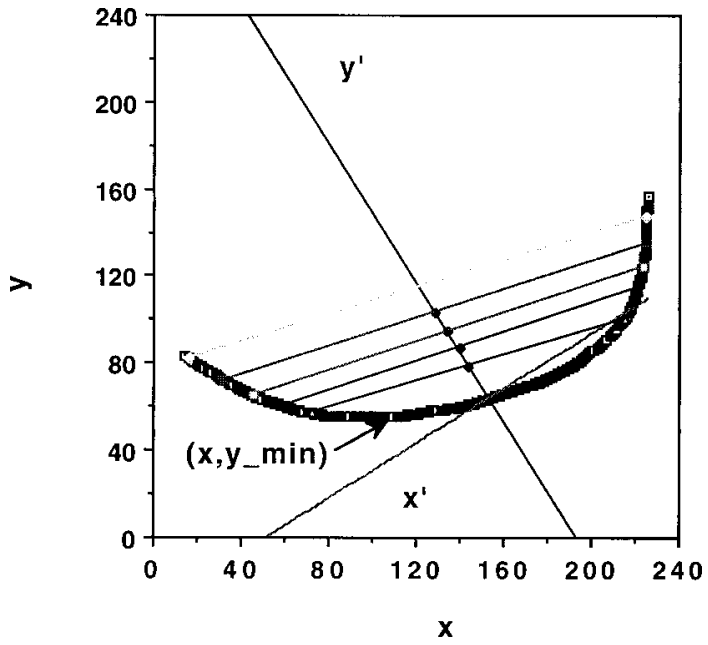

FIG. 2. Example of the $x^{\prime}-y^{\prime}$ starting axes computed with the subroutine STARTAXIS. These axes are translated and rotated to find the best fits to the borders using the equations $y^{\prime}=a x^{\prime 2}+b x^{\prime 3}$ and $y^{\prime}=a x^{\prime 2}+b x^{\prime 3}+c x^{\prime 4}$. 
through the midpoints of line segments drawn between appropriate points on the right and left sides of the borders. When suitable line segments are drawn, the border will be fairly symmetric about the line through the midpoints of the line segments, and this line should be a good starting axis for the curve fits.

The algorithm that was written to locate the initial axes, STARTAXIS, first determines the point on the border that has a minimum $y$-value, $\left(x, y_{-} \min \right)$. Next, the number of points on the border to the left and right of $\left(x, y_{-} \min \right)$ are computed. If either number is less than 25 , the topmost point on that side is selected as a starting point. Otherwise, the derivatives $(d y / d x)$ of the topmost $25 \%$ of the points on each side of $\left(x, y_{-} \min \right)$ are computed. The point at which the derivative is a minimum (most negative) on the left side of $\left(x, y_{-} \min \right)$ is selected as a starting point for the left side. Similarly, the point at which the derivative is a maximum (most positive) on the right side is selected as the starting point for the right side. (The topmost, light gray line in Fig. 2 connects the left and right starting points.) Next, the number of points between the left starting point and ( $x, y_{-}$min), and the number of points between the right starting point and $\left(x, y_{-} \min \right)$ are computed. The smaller of these two numbers is divided by 5 to create an incremental unit. Using the convention that the endpoint of the border on the left is point number 1 and the endpoint on the right is the final point, line segments are determined between points on the border corresponding with the leftmost starting point plus an integer multiple of the incremental unit and the rightmost starting point minus that same value. (See the black lines in Fig. 2) Finally, the midpoint of each line segment is computed.

The $y^{\prime}$-axis is then ascertained by least square fitting a line between the midpoints of the line segments. The intersection of this line with the border is defined to be the origin, and the $x^{\prime}$ axis is the line perpendicular to the $y^{\prime}$-axis passing through the origin (see Fig. 2).

\section{Determination of best fit by translation and rotation of axes to find the best fit}

The next task of the computer program is the translation and rotation of the axes to find the best fit of the polynomial equation to the smoothed border. Equations employed for the translation and rotation were:

$$
x^{\prime}=x_{S} \cos \theta+y_{S} \sin \theta
$$

and

$$
y^{\prime}=-x_{S} \sin \theta+y_{S} \cos \theta,
$$

where $x_{S}=x-x_{\text {origin }}+x_{\text {shift }}, y_{S}=y-y_{\text {origin }}+y_{\text {shift }}$, and $\theta$ $=(\pi / 180) \cdot\left(\theta_{\text {Start }}+\theta_{\text {shift }}\right) .\left(x_{\text {origin }}, y_{\text {origin }}\right)$ and $\theta_{\text {Start }}$ are the coordinates of the origin and the angle of the starting abscissa (in degrees relative to the $x$-axis), respectively, and $x_{\text {shift }}, y_{\text {shift }}$, and $\theta_{\text {shift }}$ are the translation and rotation values.

The fit error was defined to be the root-mean-square (rms) distance between corresponding $y$-values on the smoothed, automatically detected borders and the fitted borders. The equation utilized was

$$
\text { error }=\sqrt{\sum_{i=1}^{n}\left(y_{i}-y_{\mathrm{fit}_{\mathrm{i}}}\right)^{2} / n} .
$$

The best fit corresponded to a minimum rms error.

To improve the efficiency of this process, we first employ coarse shifts and rotations with increments of $4 \mathrm{~mm}$ and 4 degrees, respectively. We use an $x$-translation range of $+/$ $-40 \mathrm{~mm}$, a $y$-translation range of $+/-20 \mathrm{~mm}$ and rotation angle range of $+/-40$ degrees. The translation shifts $\left(x_{\text {shift }}, y_{\text {shift }}\right)$ and the angle shift $\left(\theta_{\text {shift }}\right)$ corresponding to the best fit are found. After this, finer increments of $1 \mathrm{~mm}$ and 1 degree are employed within the best "coarse" shift ranges $+/-4 \mathrm{~mm}$ and $+/-4$ degrees. For each type of fit $(y$ $=a x^{2}+b x^{3}$ and $\left.y=a x^{2}+b x^{3}+c x^{4}\right)$, the entire fitting and shifting iteration process takes about $\frac{1}{2}$ second per border on a Digital Equipment Corporation (DEC) AlphaStation. The validity of the above chosen ranges is confirmed by the fact that the fits within these ranges had average rms errors of about $2 \mathrm{~mm}$ or less and only in very rare instances (11 cases for CC and 24 for MLO including both $a, b$ and $a, b, c$ fits) did the best fit occur at the limits of translation or rotation. Furthermore, in the majority of the latter cases (e.g., 32 of 35 cases), the fit errors were less than $2.5 \mathrm{~mm}$, which is considered a very good fit.

Finally, to verify that the minima in the rms fit errors were not passed over using coarse followed by fine increments in translation and angulation, the computation was repeated in 229 cases using only fine increments. The resulting rms fit errors were on the average only 0.01 less than those using coarse followed by fine increments, the rms difference between the errors was only 0.02 , and the maximum rms difference was 0.13 . Thus in general, the minima were not passed over, and greater efficiency was achieved without sacrificing accuracy.

\section{Cluster analysis}

To classify the border shapes, the resulting best fit coefficients (either $a$ and $b$ or $a, b$, and $c$ ) for each border were introduced into a K-Means Cluster Analysis algorithm incorporated in the SPSS statistical package (SPSS Inc., Chicago, Il). This clustering method is based upon nearest neighbor sorting, whereby each case is assigned to the cluster for which the distance between the cluster center and the case is a minimum. ${ }^{20}$ Since the cluster centers are not known initially, they are iteratively estimated from the data. The coefficients for the CC-view and MLO-view borders were analyzed separately. Absolute values of the $b$-coefficients were used since the curve shapes for positive and negative $b$-values are mirror images of one another. Thus the same filter could be employed; it would simply have to be flipped 180 degrees for one of the $b$-value polarities. We used the K-Means method to classify the borders into 2, 3, 4, 5, 6, 8, and 10 clusters.

In addition, we performed limited studies of various modifications of traditional K-Means clustering. In one, which we termed the "hybrid technique," the $a$ and $b$ parameters were employed ( $c$ set to 0 ) when the fit to a given 
border using $y=a x^{2}+b x^{3}$ was better than a threshold value (e.g., when the rms error was $\leqslant 3 \mathrm{~mm}(3$ pixels)). Otherwise, the border was refit using $y=a x^{2}+b x^{3}+c x^{4}$, and the $a, b$, and $c$ parameters of that fit were employed. This hybrid method is based on the assumption that if the fit to the 2parameter equation is sufficient, it is not necessary to use a 3-parameter fit. It is further assumed that under those circumstances, use of the coefficient $(c)$ of the fourth order term only adds noise to the data being clustered.

In a second modification, we used the $Z$-scores of the variables $(a, b$, and $c)$ rather than the variables themselves in the cluster analysis. The $Z$-score is the number of standard deviations that a given variable for a particular border differs from the mean value for all borders. Such a method makes the importance of each parameter more equivalent. It compensates for the wide variations in the magnitudes of the parameters. For example, the $b$-values were about 20 to 200 times smaller than the $a$-values, and the $c$-values were about 20 to 500 times smaller than the $b$-values.

Finally, in a third modification, we first applied K-Means Cluster analysis to the entire CC border set to obtain six clusters. We then fixed the cluster membership for the two best clusters, eliminated the corresponding borders from the data set, and performed K-Means Cluster analysis on the remaining borders. The second stage cluster analysis classified the remaining borders into 4,5 , or 6 clusters. The resulting total number of clusters was 6,7 , or 8 , respectively. The underlying assumption for this method was that better clustering might be obtained in the second stage for the smaller set of borders. Thus, the overall clustering would be better than when the entire set of borders was clustered all at one time.

\section{E. Determination of filter shapes and refitting of borders}

Once the classification of each border was determined, the mean $a$ and $b$ values or mean $a, b$, and $c$ values for the borders within each class were determined. The border defined by the equation using the mean coefficients defined the "filter." A computer routine was written to translate and rotate each of the individual borders within each class to best match their corresponding "filter." This routine again utilized coarse and fine increments for translation and rotation similar to the increments employed in the original fitting routine. The translation and rotation values determined with the original fitting routine were employed as starting values for the matching routine. The rms distance between the individual border and the filter of its class was minimized as an indication of best match. For each filter or class, the mean and standard deviation of the rms distances were computed. These values were used to quantitatively assess the success of the border classification. Also, for each type of clustering, the overall mean rms distance for all of the filters was computed using the equation:

$$
\bar{d}=\sum_{g=1}^{N} \sum_{i=1}^{P_{g}} \mathrm{rms}_{i g} / T
$$

where $N$ is the total number of clusters (e.g., 2, 3, 4, 5, 6, 7, 8 or 10), $P_{g}$ is the number of borders in cluster $g, \mathrm{rms}_{i g}$ is the rms distance between border $i$ and the filter for cluster $g$, and $T$ is the total number of borders (e.g., $T=\sum_{g=1}^{N} P_{g}$ ). In addition, a figure of merit (FOM) was derived to estimate the optimal number of clusters. The equation employed was

$$
\mathrm{FOM}=\sum_{g=1}^{N}\left(P_{g} /\left(\overline{\mathrm{rms}_{g}}\right)^{2}\right) / \sqrt{N},
$$

where $P_{g}$ and $N$ are as defined above, and $\overline{\mathrm{rms}_{g}}$ is the average rms error for cluster $g$. The denominator in this equation $(\sqrt{N})$ is a term that penalizes the use of larger numbers of clusters, and the numerator gives greater weight to those clusters having greater number of borders and smaller rms errors. Finally, the newly rotated and translated borders were refit with the equations $y=a x^{2}+b x^{3}$ and $y=a x^{2}+b x^{3}$ $+c x^{4}$. The new coefficients, $(a, b)$ and $(a, b, c)$, were plotted to enable visual evaluation of the success of classification.

\section{F. Investigation of optical density and exposure values near the filter position}

The filters that will eventually be built must be customshaped in the thickness dimension to compensate for the variations in $x$-ray transmission at the periphery of the breast. To assess this effect, we computed mean optical density and mean exposure profiles along normals to the "filter" contour for one of the highly populated clusters in the classification study of CC-view mammograms. The particular cluster consisted of 231 of the 470 CC-view borders, and it was computed by the K-Means technique for the case in which there was a total of six clusters, and the borders were fit with the equation $y=a x^{2}+b x^{3}$. Twenty-one equally spaced normals were derived along the contour of the "filter." Each normal started at a position about $1 \mathrm{~cm}$ outside the "ffilter" contour and extended about $2 \mathrm{~cm}$ inside the contour (into the breast). The pixel values at the points along the normals were converted to optical densities using a pixel value to optical density transform derived from the film digitizer calibration curve. The means and standard deviations of the optical densities along each normal were computed. To convert the optical densities to x-ray exposures, which would eventually be needed for the filter design, we derived a film characteristic curve using $x$-ray sensitometry. The curve was generated with a bootstrap method using three mAs values (2, 20, and 100), four focus-to-film distances (23.5, 33.5, 47.5 , and $66.5 \mathrm{~cm}$ ), and three Lucite attenuator thicknesses $(12,24$, and $36 \mathrm{~mm})$. Within each segment, the four distances were employed at fixed $\mathrm{mAs}$ and fixed attenuator thickness. This was done to avoid errors due to reciprocity law failure and due to changes in x-ray beam quality. The curve segments were then bootstrapped together to create a characteristic curve extending over the entire exposure range. All measurements were made at $28 \mathrm{kVp}$, which is typical for the wide range of mammograms analyzed in this study. A 
TABLE I. Results of fitting the CC- and MLO-view borders with the equations $y=a x^{2}+b x^{3}$ and $y=a x^{2}+b x^{3}+c x^{4}$.

\begin{tabular}{cccc}
\hline \hline No. of \\
images & View & Type of fit & $\begin{array}{c}\text { Mean rms error } \\
\text { between fit and run- } \\
\text { length averaged } \\
\text { automatically } \\
\text { tracked border (mm) }\end{array}$ \\
\hline 470 & CC & $a, b$ & 2.18 \\
470 & CC & $a, b, c$ & 1.07 \\
484 & MLO & $a, b$ & 1.53 \\
484 & MLO & $a, b, c$ & 1.07 \\
\hline \hline
\end{tabular}

Keithley (Cleveland, Ohio) model 35050A dosimeter with a Keithley model 96035 15-cc ionization chamber was used to measure the exposures at the closest position, and the exposures at other positions were computed using the inverse square law.

\section{RESULTS}

The average rms errors for the fitting of the original runlength averaged borders with the equations $y=a x^{2}+b x^{3}$ and $y=a x^{2}+b x^{3}+c x^{4}$ are compared in Table I. The data in the fourth column of this table demonstrate that both fits are very good [errors are $\sim 2 \mathrm{~mm}$ (pixels) or less], and use of 3coefficients $(a, b, c)$ reduced the fitting errors by about $30 \%-$ $50 \%$. An example of a fitted curve for which the rms error is equal to the mean value for all MLO views $(1.53 \mathrm{~mm})$ using the $a$ and $b$ parameters is displayed in Fig. 3, below. Figure 4 illustrates a case in which the rms error was $4.03 \mathrm{~mm}$ for the two parameter $(a, b)$ fit and $1.18 \mathrm{~mm}$ for the three parameter $(a, b, c)$ fit.

Clustering results are listed in Tables II to IV. The mean rms distances or errors between individual borders within clusters and their corresponding "filters" for CC-view borders are listed in Table II and those for the MLO-view bor-

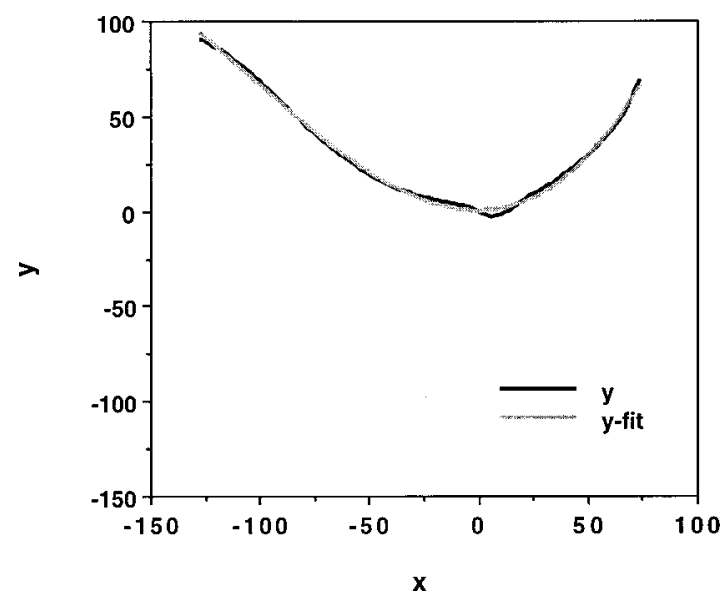

FIG. 3. Example of a fit for an MLO-view in which the fitted border (lighter curve) has an rms error of $1.53 \mathrm{~mm}$, which is equal to the mean value for all MLO-views obtained using the $a$ - and $b$-parameter fitting routine.
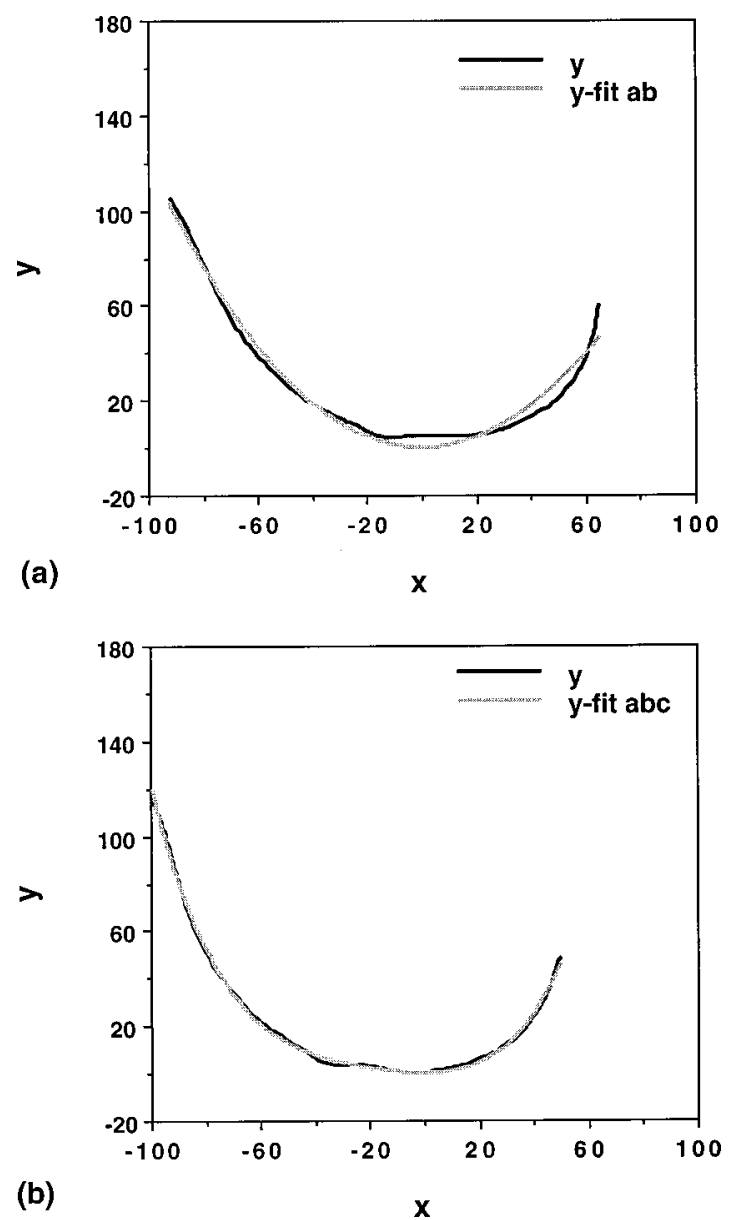

FIG. 4. Example of a case in which a fitted border using the 3-coefficient $(a, b, c)$ equation is significantly superior to that using the 2-coefficient $(a, b)$ equation. The same MLO-view border was fit using both equations. The rms error for the 2-coefficient fit (part $a$ ) is $4.03 \mathrm{~mm}$ and that for the 3-coefficient fit (part $b$ ) is $1.18 \mathrm{~mm}$.

ders are listed in Table III. The overall mean rms distances between the borders and filters for the various clustering parameters and methods are listed in Table IV.

Scattergrams displaying the original $a$ and $b$ fitting coefficients for the 470 CC-view borders and 484 MLO-view borders are shown in Fig. 5. These are the $a$ and $b$ values that are input into the K-Means Cluster analysis program. Figure 6 shows examples of the $a$ and $b$ and $a, b$, and $c$ values of the second-stage fits to the borders after they were translated and rotated to best match the cluster "filter" (the curve generated with the mean coefficients for the cluster).

Our clustering figure of merit as a function of number of clusters is plotted in Fig. 7.

Figure 8 shows an overlay of a "filter" and its associated normals on a mammogram whose automatically traced breast border was clustered to belong to the filter shape. Examples of filter shapes for the CC- and MLO-views are illustrated in Fig. 9(a) and (b), respectively.

Finally, plots of the mean film optical densities as a function of position along normals to the "filter" are shown in Fig. 10(a) and (b). As described in the Materials and Methods section, the mean values were obtained from the 231 
TABLE II. Mean rms distances (mm) between individual borders and "filters" for CC-views. (Standard deviations for each distribution are noted in parentheses.) Results in each row are ordered from the smallest mean rms distance to the largest. $n=$ number of borders in a particular cluster.

\begin{tabular}{|c|c|c|c|c|c|c|c|c|c|c|}
\hline \multirow{2}{*}{$\begin{array}{c}\text { (A). } a, b \text { fit } \\
\text { Total no. of } \\
\text { clusters }\end{array}$} & \multicolumn{10}{|c|}{ Cluster } \\
\hline & 1 & 2 & 3 & 4 & 5 & 6 & 7 & 8 & 9 & 10 \\
\hline 2 & $\begin{array}{l}2.7 \\
(1.4) \\
n=314\end{array}$ & $\begin{array}{l}3.7 \\
(2.1) \\
n=156\end{array}$ & & & & & & & & \\
\hline 3 & $\begin{array}{l}2.2 \\
(1.2) \\
n=139\end{array}$ & $\begin{array}{l}2.6 \\
(1.2) \\
n=248\end{array}$ & $\begin{array}{l}4.1 \\
(2.4) \\
n=83\end{array}$ & & & & & & & \\
\hline 4 & $\begin{array}{l}2.0 \\
(1.1) \\
n=93\end{array}$ & $\begin{array}{l}2.4 \\
(1.1) \\
n=235\end{array}$ & $\begin{array}{l}3.5 \\
(4.0) \\
n=9\end{array}$ & $\begin{array}{l}3.6 \\
(2.0) \\
n=133\end{array}$ & & & & & & \\
\hline 5 & $\begin{array}{l}2.1 \\
(1.1) \\
n=137\end{array}$ & $\begin{array}{l}2.5 \\
(1.2) \\
n=232\end{array}$ & $\begin{array}{l}3.5 \\
(4.1) \\
n=9\end{array}$ & $\begin{array}{l}3.7 \\
(2.7) \\
n=4\end{array}$ & $\begin{array}{l}3.8 \\
(2.1) \\
n=88\end{array}$ & & & & & \\
\hline 6 & $\begin{array}{l}2.1 \\
(1.1) \\
n=131\end{array}$ & $\begin{array}{l}2.5 \\
(1.2) \\
n=231\end{array}$ & $\begin{array}{l}3.1 \\
(3.3) \\
n=5\end{array}$ & $\begin{array}{l}3.7 \\
(2.7) \\
n=4\end{array}$ & $\begin{array}{l}3.7 \\
(2.1) \\
n=95\end{array}$ & $\begin{array}{l}3.9 \\
(6.1) \\
n=4\end{array}$ & & & & \\
\hline $\begin{array}{l}6(2 \text { best from } 6 \\
\text { clusters }+ \\
\text { recluster } \\
\text { remaining into }\end{array}$ & $\begin{array}{l}2.1 \\
(1.1) \\
n=131\end{array}$ & $\begin{array}{l}2.5 \\
(1.2) \\
n=231\end{array}$ & $\begin{array}{l}3.4 \\
(2.1) \\
n=60\end{array}$ & $\begin{array}{l}3.5 \\
(4.1) \\
n=9\end{array}$ & $\begin{array}{l}3.7 \\
(2.7) \\
n=4\end{array}$ & $\begin{array}{l}3.8 \\
(2.1) \\
n=35\end{array}$ & & & & \\
\hline $\begin{array}{l}4 \text { clusters) } \\
7 \text { (2 best from } 6 \\
\text { clusters }+ \\
\text { recluster } \\
\text { remaining into }\end{array}$ & $\begin{array}{l}2.1 \\
(1.1) \\
n=131\end{array}$ & $\begin{array}{l}2.5 \\
(1.2) \\
n=231\end{array}$ & $\begin{array}{l}3.4 \\
(2.1) \\
n=60\end{array}$ & $\begin{array}{l}3.4 \\
(2.9) \\
n=2\end{array}$ & $\begin{array}{l}3.5 \\
(4.1) \\
n=9\end{array}$ & $\begin{array}{l}3.8 \\
(2.0) \\
n=35\end{array}$ & $\begin{array}{l}3.8 \\
(2.9) \\
n=2\end{array}$ & & & \\
\hline $\begin{array}{l}5 \text { clusters) } \\
8 \text { ( } 2 \text { best from } 6 \\
\text { clusters }+ \\
\text { recluster } \\
\text { remaining into } \\
6 \text { clusters) }\end{array}$ & $\begin{array}{l}2.1 \\
(1.1) \\
n=131\end{array}$ & $\begin{array}{l}2.5 \\
(1.2) \\
n=231\end{array}$ & $\begin{array}{l}3.1 \\
(3.3) \\
n=5\end{array}$ & $\begin{array}{l}3.4 \\
(2.2) \\
n=55\end{array}$ & $\begin{array}{l}3.4 \\
(2.9) \\
n=2\end{array}$ & $\begin{array}{l}3.7 \\
(1.9) \\
n=40\end{array}$ & $\begin{array}{l}3.8 \\
(2.9) \\
n=2\end{array}$ & $\begin{array}{l}3.9 \\
(6.1) \\
n=4\end{array}$ & & \\
\hline 8 & $\begin{array}{l}1.7 \\
(0.9) \\
n=52\end{array}$ & $\begin{array}{l}2.0 \\
(0.9) \\
n=119\end{array}$ & $\begin{array}{l}2.3 \\
(1.2) \\
n=144\end{array}$ & $\begin{array}{l}3.0 \\
(1.7) \\
n=93\end{array}$ & $\begin{array}{l}3.1 \\
(3.3) \\
n=5\end{array}$ & $\begin{array}{l}3.7 \\
(2.7) \\
n=4\end{array}$ & $\begin{array}{l}3.8 \\
(2.3) \\
n=49\end{array}$ & $\begin{array}{l}3.9 \\
(6.1) \\
n=4\end{array}$ & & \\
\hline 10 & $\begin{array}{l}0.9 \\
(0) \\
n=1\end{array}$ & $\begin{array}{l}1.7 \\
(0.9) \\
n=52\end{array}$ & $\begin{array}{l}2.0 \\
(0.9) \\
n=113\end{array}$ & $\begin{array}{l}2.3 \\
(1.2) \\
n=145\end{array}$ & $\begin{array}{l}2.8 \\
(1.5) \\
n=89\end{array}$ & $\begin{array}{l}3.2 \\
(3.1) \\
n=4\end{array}$ & $\begin{array}{l}3.4 \\
(2.9) \\
n=2\end{array}$ & $\begin{array}{l}3.8 \\
(2.9) \\
n=2\end{array}$ & $\begin{array}{l}3.9 \\
(2.3) \\
n=58\end{array}$ & $\begin{array}{l}3.9 \\
6.1) \\
n=4\end{array}$ \\
\hline \multirow{2}{*}{$\begin{array}{c}\text { (B). } a, b, c \text { fit } \\
\text { Total no. of } \\
\text { clusters }\end{array}$} & \multicolumn{10}{|c|}{ Cluster } \\
\hline & 1 & 2 & 3 & 4 & 5 & 6 & 7 & 8 & 9 & 10 \\
\hline 2 & $\begin{array}{l}2.9 \\
(1.7) \\
n=82\end{array}$ & $\begin{array}{l}3.1 \\
(2.0) \\
n=388\end{array}$ & & & & & & & & \\
\hline 3 & $\begin{array}{l}2.8 \\
(1.7) \\
n=175\end{array}$ & $\begin{array}{l}3.2 \\
(2.0) \\
n=23\end{array}$ & $\begin{array}{l}3.2 \\
(2.1) \\
n=272\end{array}$ & & & & & & & \\
\hline 4 & $\begin{array}{l}2.7 \\
(1.8) \\
n=205\end{array}$ & $\begin{array}{l}2.9 \\
(1.9) \\
n=60\end{array}$ & $\begin{array}{l}3.2 \\
(2.0) \\
n=199\end{array}$ & $\begin{array}{l}3.6 \\
(2.2) \\
n=6\end{array}$ & & & & & & \\
\hline 5 & $\begin{array}{l}2.4 \\
(1.4) \\
n=34\end{array}$ & $\begin{array}{l}2.7 \\
(1.7) \\
n=136\end{array}$ & $\begin{array}{l}3.0 \\
(2.0) \\
n=202\end{array}$ & $\begin{array}{l}3.6 \\
(2.4) \\
n=92\end{array}$ & $\begin{array}{l}3.6 \\
(2.2) \\
n=6\end{array}$ & & & & & \\
\hline 6 & $\begin{array}{l}1.0 \\
(0.0) \\
n=1\end{array}$ & $\begin{array}{l}2.4 \\
(1.4) \\
n=34\end{array}$ & $\begin{array}{l}2.7 \\
(1.7) \\
n=136\end{array}$ & $\begin{array}{l}2.9 \\
(2.2) \\
n=5\end{array}$ & $\begin{array}{l}3.0 \\
(2.0) \\
n=204\end{array}$ & $\begin{array}{l}3.6 \\
(2.4) \\
n=90\end{array}$ & & & & \\
\hline 6 hybrid $^{\mathrm{a}}$ & $\begin{array}{l}1.7 \\
(2.0) \\
n=7\end{array}$ & $\begin{array}{l}2.0 \\
(1.1) \\
n=157\end{array}$ & $\begin{array}{l}2.2 \\
(0.7) \\
n=48\end{array}$ & $\begin{array}{l}2.3 \\
(1.9) \\
n=139\end{array}$ & $\begin{array}{l}4.2 \\
(2.8) \\
n=80\end{array}$ & $\begin{array}{l}4.5 \\
(2.8) \\
n=44\end{array}$ & & & & \\
\hline $\begin{array}{l}6 \text { using } \\
Z \text {-scores }\end{array}$ & $\begin{array}{l}1.0 \\
(0.0) \\
n=1\end{array}$ & $\begin{array}{l}1.3 \\
(0.8) \\
n=2\end{array}$ & $\begin{array}{l}1.4 \\
(0.0) \\
n=1\end{array}$ & $\begin{array}{l}2.6 \\
(1.6) \\
n=136\end{array}$ & $\begin{array}{l}3.1 \\
(2.0) \\
n=309\end{array}$ & $\begin{array}{l}4.4 \\
(4.1) \\
n=21\end{array}$ & & & & \\
\hline 8 & $\begin{array}{l}1.0 \\
(0.0) \\
n=1\end{array}$ & $\begin{array}{l}1.3 \\
(0.0) \\
n=1\end{array}$ & $\begin{array}{l}1.8 \\
(1.0) \\
n=4\end{array}$ & $\begin{array}{l}2.4 \\
(1.5) \\
n=28\end{array}$ & $\begin{array}{l}2.7 \\
(1.6) \\
n=109\end{array}$ & $\begin{array}{l}2.8 \\
(2.0) \\
n=130\end{array}$ & $\begin{array}{l}3.0 \\
(1.8) \\
n=145\end{array}$ & $\begin{array}{l}4.0 \\
(2.7) \\
n=52\end{array}$ & & \\
\hline 8 hybrid $^{\text {a }}$ & $\begin{array}{l}0.8 \\
(0.1) \\
n=3\end{array}$ & $\begin{array}{l}1.9 \\
(1.8) \\
n=4\end{array}$ & $\begin{array}{l}2.0 \\
(1.1) \\
n=140\end{array}$ & $\begin{array}{l}2.1 \\
(1.5) \\
n=134\end{array}$ & $\begin{array}{l}2.2 \\
(0.6) \\
n=44\end{array}$ & $\begin{array}{l}3.7 \\
(2.2) \\
n=52\end{array}$ & $\begin{array}{l}4.1 \\
(3.8) \\
n=66\end{array}$ & $\begin{array}{l}4.6 \\
(3.0) \\
n=27\end{array}$ & & \\
\hline 10 & $\begin{array}{l}0.7 \\
(0.0) \\
n=1\end{array}$ & $\begin{array}{l}1.0 \\
(0.0) \\
n=1\end{array}$ & $\begin{array}{l}1.3 \\
(0.0) \\
n=1\end{array}$ & $\begin{array}{l}2.1 \\
(1.0) \\
n=3\end{array}$ & $\begin{array}{l}2.4 \\
(1.5) \\
n=28\end{array}$ & $\begin{array}{l}2.7 \\
(1.6) \\
n=103\end{array}$ & $\begin{array}{l}2.8 \\
(2.0) \\
n=107\end{array}$ & $\begin{array}{l}2.9 \\
(1.7) \\
n=122\end{array}$ & $\begin{array}{l}3.1 \\
(2.0) \\
n=72\end{array}$ & $\begin{array}{l}4.2 \\
(2.8) \\
n=32\end{array}$ \\
\hline
\end{tabular}

${ }^{\mathrm{a}}$ Hybrid $=$ use $a, b$ coefficients $(c=0)$ when original fit error $\leqslant 3.0 \mathrm{~mm}$, use $a, b, c$ coefficients when original fit error $>3.0 \mathrm{~mm}$. 
TABLE III. Mean rms distances $(\mathrm{mm})$ between individual borders and "filters" for MLO-views. (Standard deviations for each distribution are noted in parentheses.) Results in each row are ordered from the smallest mean rms distance to the largest. $n=$ number of borders in a particular cluster.

\begin{tabular}{|c|c|c|c|c|c|c|c|c|c|c|}
\hline \multirow{2}{*}{$\begin{array}{l}\text { (A). } a, b \text { fit } \\
\text { Total no. of } \\
\text { clusters }\end{array}$} & \multicolumn{10}{|c|}{ Cluster } \\
\hline & 1 & 2 & 3 & 4 & 5 & 6 & 7 & 8 & 9 & 10 \\
\hline 2 & $\begin{array}{l}2.2 \\
(1.1) \\
n=306\end{array}$ & $\begin{array}{l}3.2 \\
(1.9) \\
n=178\end{array}$ & & & & & & & & \\
\hline 3 & $\begin{array}{l}1.9 \\
(0.9) \\
n=172\end{array}$ & $\begin{array}{l}2.2 \\
(1.1) \\
n=227\end{array}$ & $\begin{array}{l}3.5 \\
(2.0) \\
n=85\end{array}$ & & & & & & & \\
\hline 4 & $\begin{array}{l}1.7 \\
(0.7) \\
n=107\end{array}$ & $\begin{array}{l}1.9 \\
(0.8) \\
n=219\end{array}$ & $\begin{array}{l}2.9 \\
(1.4) \\
n=134\end{array}$ & $\begin{array}{l}4.1 \\
(1.9) \\
n=24\end{array}$ & & & & & & \\
\hline 5 & $\begin{array}{l}1.7 \\
(0.7) \\
n=154\end{array}$ & $\begin{array}{l}1.8 \\
(0.8) \\
n=58\end{array}$ & $\begin{array}{l}2.2 \\
(1.1) \\
n=185\end{array}$ & $\begin{array}{l}3.4 \\
(1.8) \\
n=83\end{array}$ & $\begin{array}{l}4.0 \\
(3.1) \\
n=4\end{array}$ & & & & & \\
\hline 6 & $\begin{array}{l}1.6 \\
(0.7) \\
n=109\end{array}$ & $\begin{array}{l}1.9 \\
(0.8) \\
n=179\end{array}$ & $\begin{array}{l}2.1 \\
(0.7) \\
n=18\end{array}$ & $\begin{array}{l}2.5 \\
(1.3) \\
n=129\end{array}$ & $\begin{array}{l}3.3 \\
(3.1) \\
n=3\end{array}$ & $\begin{array}{l}3.7 \\
(1.9) \\
n=46\end{array}$ & & & & \\
\hline 8 & $\begin{array}{l}0.6 \\
(0.0) \\
n=1\end{array}$ & $\begin{array}{l}0.8 \\
(0.0) \\
n=1\end{array}$ & $\begin{array}{l}1.6 \\
(0.7) \\
n=142\end{array}$ & $\begin{array}{l}1.8 \\
(0.8) \\
n=64\end{array}$ & $\begin{array}{l}2.0 \\
(0.8) \\
n=165\end{array}$ & $\begin{array}{l}3.0 \\
(1.4) \\
n=87\end{array}$ & $\begin{array}{l}4.0 \\
(2.0) \\
n=22\end{array}$ & $\begin{array}{l}4.0 \\
(3.2) \\
n=2\end{array}$ & & \\
\hline 10 & $\begin{array}{l}0.6 \\
(0.0) \\
n=1\end{array}$ & $\begin{array}{l}0.8 \\
(0.0) \\
n=1\end{array}$ & $\begin{array}{l}1.5 \\
(0.6) \\
n=81\end{array}$ & $\begin{array}{l}1.5 \\
(0.0) \\
n=1\end{array}$ & $\begin{array}{l}1.7 \\
(0.7) \\
n=117\end{array}$ & $\begin{array}{l}1.9 \\
(0.8) \\
n=150\end{array}$ & $\begin{array}{l}2.1 \\
(0.7) \\
n=17\end{array}$ & $\begin{array}{l}2.8 \\
(1.4) \\
n=71\end{array}$ & $\begin{array}{l}3.3 \\
(1.6) \\
n=35\end{array}$ & $\begin{array}{l}4.8 \\
(2.3) \\
n=10\end{array}$ \\
\hline \multicolumn{10}{|l|}{ (B). $a, b, c$ fit } & \\
\hline clusters & 1 & 2 & 3 & 4 & 5 & 6 & 7 & 8 & 9 & 10 \\
\hline 2 & $\begin{array}{l}2.9 \\
(2.2) \\
n=191\end{array}$ & $\begin{array}{l}3.6 \\
(2.3) \\
n=293\end{array}$ & & & & & & & & \\
\hline 3 & $\begin{array}{l}2.7 \\
(2.3) \\
n=234\end{array}$ & $\begin{array}{l}3.1 \\
(1.9) \\
n=81\end{array}$ & $\begin{array}{l}3.9 \\
(2.4) \\
n=169\end{array}$ & & & & & & & \\
\hline 4 & $\begin{array}{l}2.9 \\
(2.2) \\
n=229\end{array}$ & $\begin{array}{l}2.9 \\
(2.2) \\
n=123\end{array}$ & $\begin{array}{l}4.0 \\
(2.5) \\
n=130\end{array}$ & $\begin{array}{l}6.4 \\
(1.6) \\
n=2\end{array}$ & & & & & & \\
\hline 5 & $\begin{array}{l}2.4 \\
(1.9) \\
n=188\end{array}$ & $\begin{array}{l}3.0 \\
(2.3) \\
n=81\end{array}$ & $\begin{array}{l}3.2 \\
(2.2) \\
n=153\end{array}$ & $\begin{array}{l}4.9 \\
(3.0) \\
n=60\end{array}$ & $\begin{array}{l}6.4 \\
(1.6) \\
n=2\end{array}$ & & & & & \\
\hline 6 & $\begin{array}{l}2.3 \\
(2.1) \\
n=140\end{array}$ & $\begin{array}{l}2.9 \\
(1.8) \\
n=71\end{array}$ & $\begin{array}{l}3.3 \\
(2.4) \\
n=147\end{array}$ & $\begin{array}{l}3.7 \\
(2.3) \\
n=111\end{array}$ & $\begin{array}{l}4.8 \\
(3.3) \\
n=13\end{array}$ & $\begin{array}{l}6.4 \\
(1.6) \\
n=2\end{array}$ & & & & \\
\hline $\begin{array}{l}6 \\
\text { Hybrid }^{\mathrm{a}}\end{array}$ & $\begin{array}{l}1.5 \\
(0.3) \\
n=2\end{array}$ & $\begin{array}{l}2.1 \\
(1.5) \\
n=138\end{array}$ & $\begin{array}{l}2.4 \\
(2.4) \\
n=152\end{array}$ & $\begin{array}{l}2.6 \\
(1.1) \\
n=65\end{array}$ & $\begin{array}{l}3.3 \\
(3.0) \\
n=106\end{array}$ & $\begin{array}{l}5.5 \\
(4.8) \\
n=21\end{array}$ & & & & \\
\hline 8 & $\begin{array}{l}0.3 \\
(0.0) \\
n=1\end{array}$ & $\begin{array}{l}1.3 \\
(0.0) \\
n=1\end{array}$ & $\begin{array}{l}2.6 \\
(2.0) \\
n=127\end{array}$ & $\begin{array}{l}2.6 \\
(1.4) \\
n=53\end{array}$ & $\begin{array}{l}2.7 \\
(2.7) \\
n=76\end{array}$ & $\begin{array}{l}3.3 \\
(2.3) \\
n=115\end{array}$ & $\begin{array}{l}3.7 \\
(2.4) \\
n=98\end{array}$ & $\begin{array}{l}4.8 \\
(3.3) \\
n=13\end{array}$ & & \\
\hline 10 & $\begin{array}{l}0.3 \\
(0.0) \\
n=1\end{array}$ & $\begin{array}{l}1.3 \\
(0.0) \\
n=1\end{array}$ & $\begin{array}{l}2.4 \\
(2.4) \\
n=78\end{array}$ & $\begin{array}{l}2.8 \\
(2.0) \\
n=114\end{array}$ & $\begin{array}{l}2.8 \\
(1.0) \\
n=13\end{array}$ & $\begin{array}{l}2.8 \\
(1.5) \\
n=28\end{array}$ & $\begin{array}{l}3.2 \\
(2.0) \\
n=76\end{array}$ & $\begin{array}{l}3.4 \\
(2.4) \\
n=97\end{array}$ & $\begin{array}{l}3.5 \\
(3.2) \\
n=7\end{array}$ & $\begin{array}{l}4.9 \\
(3.4) \\
n=41\end{array}$ \\
\hline
\end{tabular}

${ }^{\mathrm{a}} \mathrm{Hybrid}=$ use $a, b$ coefficients $(c=0)$ when original fit error $\leqslant 3.0 \mathrm{~mm}$, use $a, b, c$ coefficients when original fit error $>3.0 \mathrm{~mm}$.

mammograms containing compressed breast borders that were classified to belong to a particular cluster. The clustering involved $470 \mathrm{CC}$-view borders which were classified into six groups using $a$ and $b$ parameters. Curves depicting the mean $+/-1$ standard deviation for several of the normals are shown in Fig. 10(c). Figure 10(d) depicts the mean rela- tive $\mathrm{x}$-ray exposures at the film plane as a function of position along the normals.

\section{DISCUSSION}

Even though the original fits are better for three coefficients $(a, b$, and $c)$ instead of two $(a$ and $b)$ (see Table I), 
TABLE IV. Overall mean rms distance between individual borders and "filters."

\begin{tabular}{|c|c|c|c|c|}
\hline \multirow[b]{2}{*}{ Total no. of clusters } & \multicolumn{4}{|c|}{ Overall mean rms error $(\mathrm{mm})$} \\
\hline & $\begin{array}{c}\text { CC-View } \\
a b \text {-fit }\end{array}$ & $\begin{array}{c}\text { CC-View } \\
a b c \text {-fit }\end{array}$ & $\begin{array}{c}\text { MLO-View } \\
a b \text {-fit }\end{array}$ & $\begin{array}{c}\text { MLO-View } \\
a b c \text {-fit }\end{array}$ \\
\hline 2 & 3.02 & 3.11 & 2.54 & 3.34 \\
\hline 3 & 2.73 & 3.05 & 2.33 & 3.18 \\
\hline 4 & 2.68 & 2.97 & 2.25 & 3.24 \\
\hline 5 & 2.67 & 2.98 & 2.19 & 3.11 \\
\hline 6 & 2.66 & 2.97 & 2.18 & 3.12 \\
\hline 8 & 2.48 & 2.91 & 2.12 & 3.07 \\
\hline 10 & 2.48 & 2.89 & 2.09 & 3.11 \\
\hline 6 hybrid & - & 2.69 & - & 2.68 \\
\hline 6 using $Z$-scores & - & 2.99 & - & - \\
\hline $\begin{array}{l}6 \text { ( } 2 \text { best from } 6 \text { clusters } \\
+ \text { recluster remaining } \\
\text { into } 4 \text { clusters) }\end{array}$ & 2.63 & - & - & - \\
\hline $\begin{array}{l}7 \text { ( } 2 \text { best from } 6 \text { clusters } \\
+ \text { recluster remaining } \\
\text { into } 5 \text { clusters) }\end{array}$ & 2.63 & - & - & - \\
\hline $\begin{array}{l}8 \text { ( } 2 \text { best from } 6 \text { clusters } \\
+ \text { recluster remaining } \\
\text { into } 6 \text { clusters) }\end{array}$ & 2.62 & - & - & - \\
\hline 8 hybrid & - & 3.03 & - & - \\
\hline
\end{tabular}

there is either only slight improvement [e.g., for 6 clusters in the CC case (Table II A, B)] or no improvement [for the MLO case (Table III A, B)] in the clustering success as measured by the mean rms distances between the individual borders within a class and the mean border or "filter." In fact, the overall mean rms error results listed in Table IV indicate that, in general, better matches between the individual borders and the filters are achieved when the filters are based upon the $a, b$ clustering. Therefore, the 2-coefficient fit is preferred.

The number of filters to be employed in our exposure equalization method must be a compromise between goodness-of-fit and practicality. The results in Table IV indicate the goodness-of-fit, as represented by the overall mean rms distance error, generally improves as the number of clusters increases. However, this improvement is not very great beyond three or four clusters. The individual cluster results in Tables II and III also exhibit this trend, and the figures of merit that were derived (see Fig. 7) peak at about three clusters. Therefore, three or four filter shapes for each view appear to be optimum.

The hybrid approach of using $a$ and $b$ values with $c$ set to zero when the original fit to the automatically traced border is less than or equal to a threshold value and using $a, b$, and $c$ values otherwise improves the clustering relative to use of the conventional $a, b$, and $c$ values in some cases (e.g., Table III B), but degrades clustering in others (e.g., Table II B). However, for all of the hybrid cases shown in the tables, the corresponding clustering that is obtained using the same total number of clusters and only the $a$ and $b$ parameters of the fit equation $y=a x^{2}+b x^{3}$ yields superior results.

Use of the $Z$-scores of the $a, b$, and $c$ values rather than the values themselves did not improve clustering (Table II B). The effect of employing the two best clusters of six from
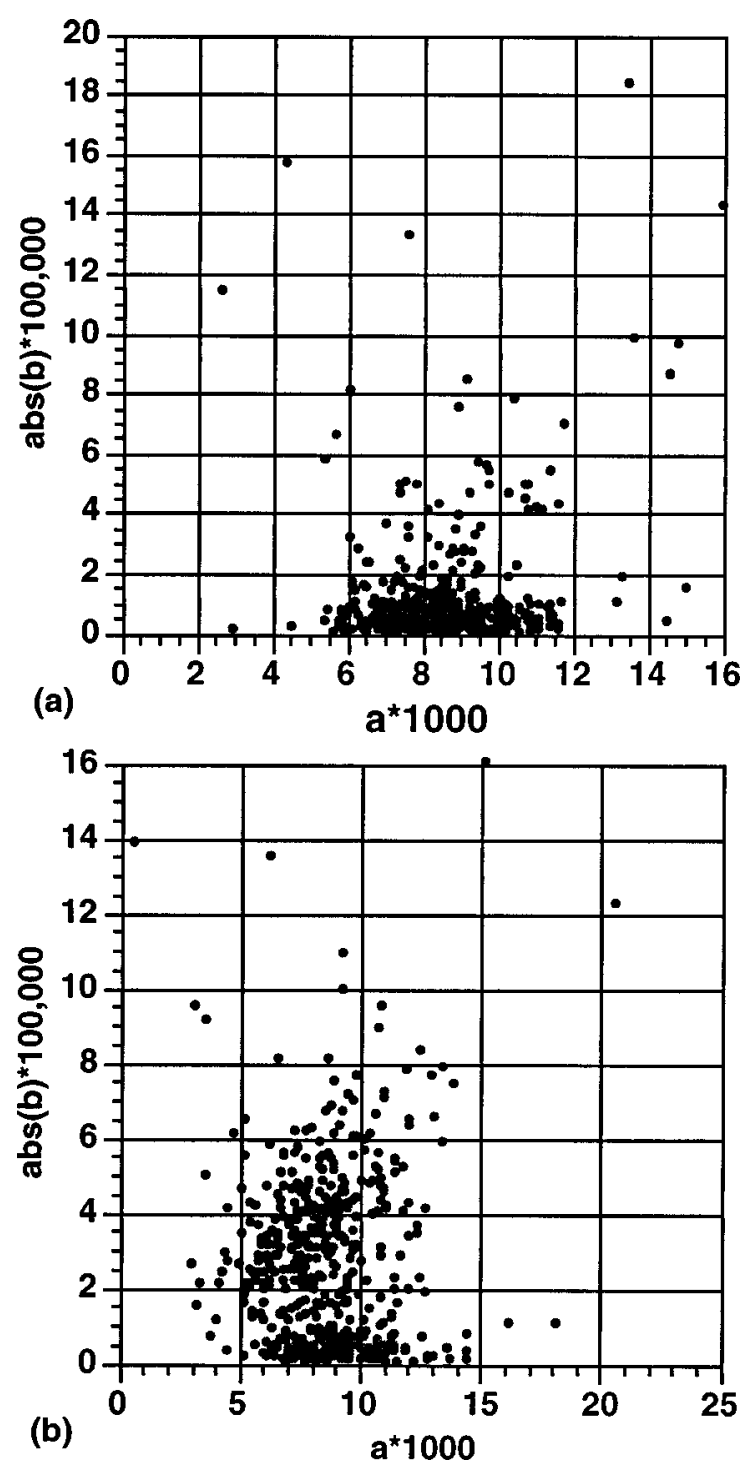

FIG. 5. Plots of $a$ and $b$ values of original $y=a x^{2}+b x^{3}$ fits to borders of (a) $470 \mathrm{CC}$-view and (b) 484 MLO-view mammograms. Absolute values of $b$ are plotted since the shapes of the curves for positive and negative $b$-values are mirror images of one another.

an initial cluster analysis followed by reclustering the remaining borders into 4,5 , or 6 groups was an insignificant $(\sim 1.2 \%-1.5 \%)$ improvement.

Figure 10(c) provides an example of the variability in the optical densities near the periphery of the breast that might be expected for a set of compressed breasts classified to be of a particular shape. The standard deviations of the optical densities range from about 0.2 to $0.6 \mathrm{OD}$. This translates to a fairly wide range of exposure values, especially in the high density region just outside the breast border. Our calculations show that, in this region, the mean exposure to the film minus 1 standard deviation is about half the mean exposure value. The mean exposure to the film plus 1 standard deviation could not be determined just outside the breast because these exposures are in the shoulder region of the film characteristic curve, where there are large uncertainties in the optical density to relative exposure conversion. Also, the op- 

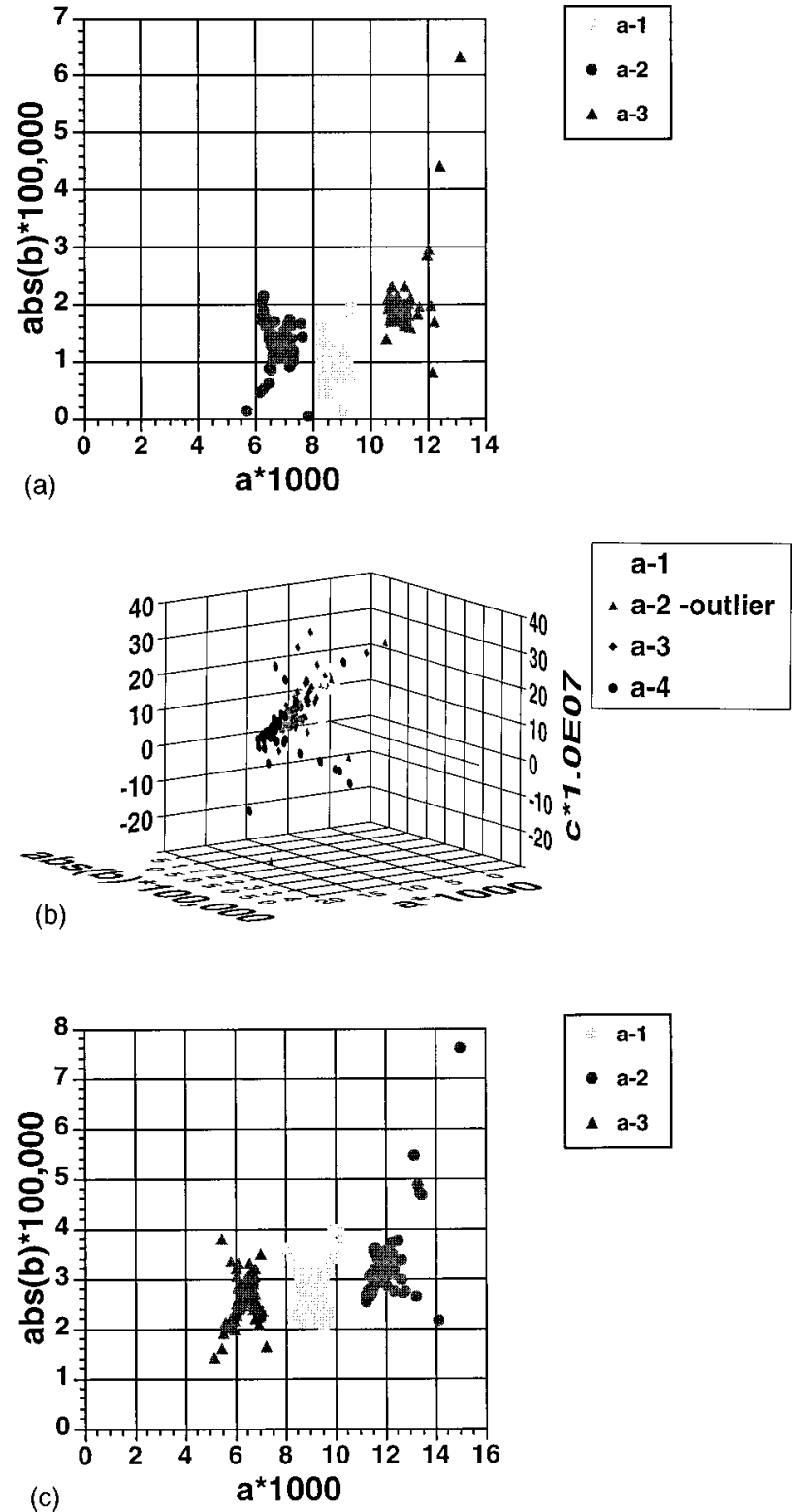

FIG. 6. Pictorial representations of clustering. The borders that are classified into each cluster are translated and rotated to best match the average border (filter) for that cluster, and they are then re-fit with the equations $y=a x^{2}$ $+b x^{3}$ and $y=a x^{2}+b x^{3}+c x^{4}$. The resulting $a, b$, or $a, b$, and $c$ coefficients are plotted. Part (a) shows the $a, b$ coefficients, and part (b) shows the $a, b$, and $c$ coefficients that are generated when the $470 \mathrm{CC}$-view borders were clustered into 3-groups for $a, b$ and 4-groups for $a, b, c$. (The outlier in the second group for the $a, b, c$ clustering had $\left(a^{*} 1000, b^{*} 100,000, c^{*} 10^{7}\right)$ coordinates of $(5.1,93.4,-71.7)$ and was not plotted so the other data points could be better visualized.) Part (c) shows the $a, b$ coefficients that are generated when the 484 MLO-view borders were clustered into three groups. The particular sets shown represent the better clustering results based on the figure of merit criteria for $a, b$ clustering, and a close to minimum overall mean rms error for $a, b, c$ clustering (see Fig. 7 and Table IV).

tical densities in this region could not be digitized to good accuracy with our film digitizer. A review of Fig. 10(c) also shows that the optical density ranges within the breast are about as variable as those outside the breast for the mammograms in this cluster. Some of this variability can be attributed to differences in breast thickness and composition in the

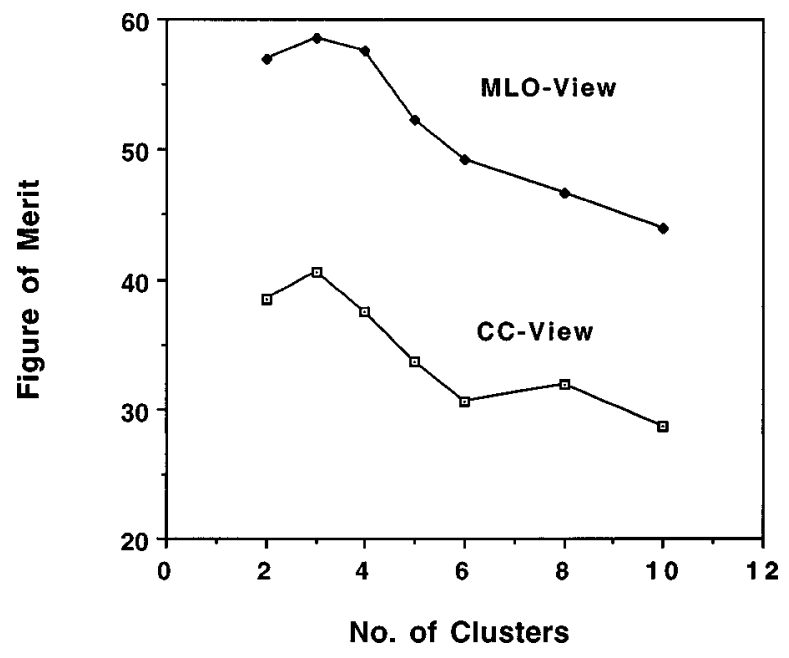

FIG. 7. Plots of clustering figure of merit as a function of number of clusters for the $\mathrm{CC}$ - and MLO-views. Both exhibit maximum figure of merits at about three clusters.

regions and some can be attributed to variations in phototimer response, technique $(\mathrm{kVp})$, and film processor conditions.

It is possible that up to three filters of different degrees of equalization will be necessary for the dense, mixed dense and fatty, and fatty breasts or for the thick, medium, and thin breasts in the same breast shape class. We plan to conduct further studies to determine the acceptable range of variation in the primary exposure profiles for each filter subclass. Once the filter subclass criteria are set and the breast images are grouped into the subclasses, the average primary exposure profile of the breast images in a given filter subclass will be

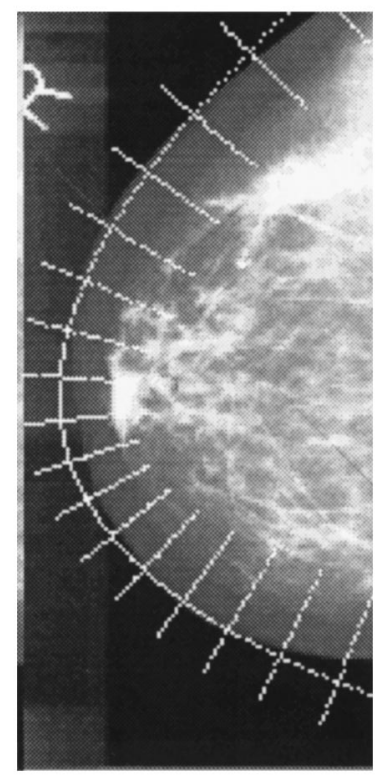

FIG. 8. Example showing overlay of "filter' contour and normals to that contour on one of the mammograms that is classified to belong to the filter shape. The mammogram was histogram equalized using NIH Image to better visualize the breast tissue out to the periphery. The rms distance error to the average "filter"' shape is $3.19 \mathrm{~mm}$ for this case. 

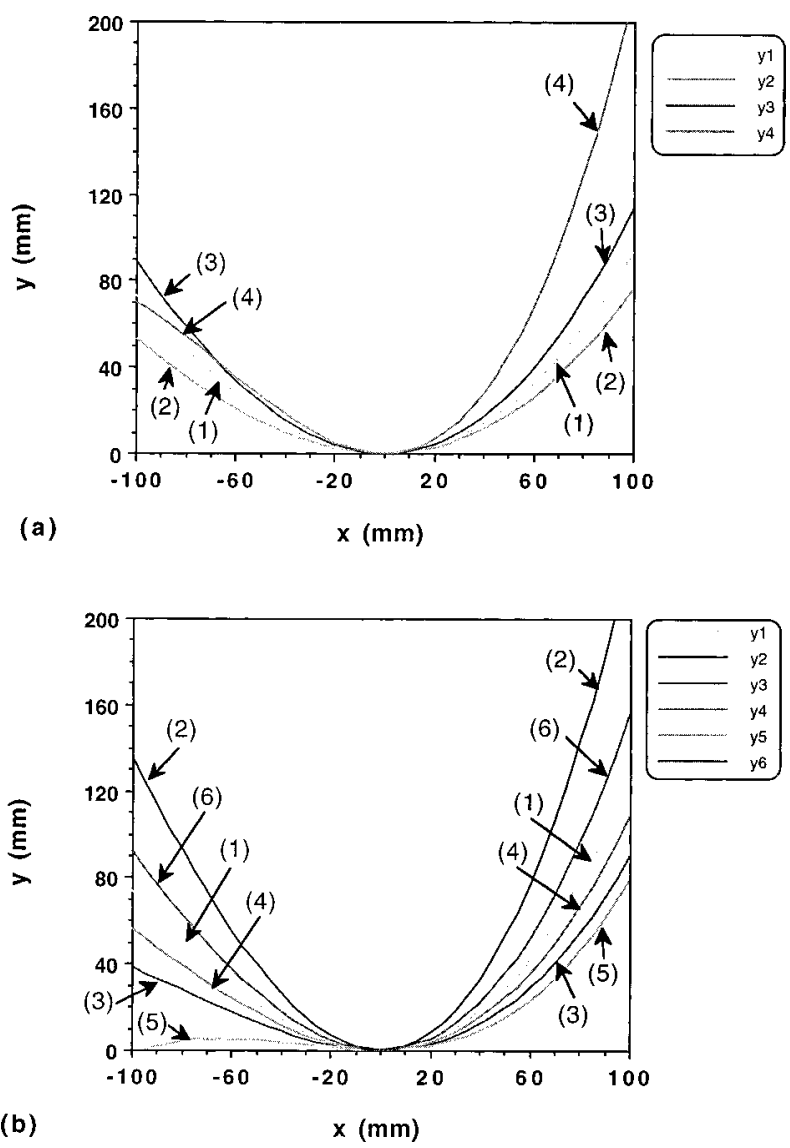

FIG. 9. Examples of "filter" shapes. (a) represents the "filter" shapes derived when the $470 \mathrm{CC}$-view borders were clustered into 4 groups using the $y=a x^{2}+b x^{3}$ fitting equation. (b) represents the "filter shapes derived when the 484 MLO-view borders were clustered into six groups using the $y$ $=a x^{2}+b x^{3}$ fitting equation. The number of borders that are classified as being the same shape as the filters in (a) are: 235 for filter \#1, 93 for filter $\# 2,133$ for filter \#3, and 9 for filter \#4. The number of borders that are classified as being the same shape as the filters in (b) are 129 for filter \#1, 3 for filter \#2, 109 for filter \#3, 179 for filter \#4, 18 for filter \#5, and 46 for filter \#6.

estimated by averaging the primary exposure profiles obtained from the individual mammograms in that subclass. The thickness profile of a filter for this subclass can then be derived for a given filter material.

The significance of this study is that, using a large data base of about 500 mammograms in each view, the results support our hypothesis that a small number of pre-fabricated filters will be sufficient to allow selection of a nearly patientspecific filter for each breast being examined. This is the basis of our approach to exposure equalization in mammographic imaging. With this technique, the dynamic range of the $\mathrm{x}$-ray intensities incident on the recording system will be reduced and the entire image can be recorded in the high contrast region of the film. The improved image quality can be achieved without additional radiation dose to the patient. Furthermore, a very high-contrast mammographic technique may be developed in combination with exposure equalization to further improve the signal-to-noise ratio (SNR) of the subtle lesions in the entire breast. We expect that the optimized technique will significantly improve the detectability of cancers in mixed and dense breasts and increase the efficacy of mammography as a screening and diagnostic tool for breast cancers.

In this work, we assumed that an rms fitting error between the filter contour and a particular breast border of 2 or $3 \mathrm{~mm}$ would be acceptable. We based this assumption on the fact that the filter will be smoothly shaped in the thickness dimension as well, which should result in a smooth exposure gradient rather than a step function. Therefore, small gaps between the breast and filter borders should be smoothed out in exposure space.

Mismatches between the filter exposure compensation profiles and the breast attenuation profiles can in practice result in artifacts. For example, if a portion of the filter extends too far toward the inside of the breast, the exposure in this region will be reduced too much, resulting in a light (low optical density) area in the mammogram. Such overcompensation is likely to occur in the MLO-view in the pectoral region where the filters, in general, do not match the breast shapes as well. The filters may have to be designed to have more gradual compensation in these regions to reduce artifacts. To better understand the potential for artifact production and the acceptable rms fitting errors, we are performing a simulation study in which exposure profiles generated in the present study are employed to construct simulated filters which are then applied to images belonging to particular compressed breast shape classes. The results of that study will be presented in a future publication.

Finally, it should be mentioned that our plans for the eventual implementation of the equalization technique do not require the use of a pre-exposure $\mathrm{x}$-ray mammogram of the patient for filter selection. Rather, the filter will be selected based on the measured thickness of the patient's compressed breast, the breast contour as determined from a visible light image of the compressed breast recorded by a TV camera that is interfaced to a computer, and the clustering results gained from a large database of digitized mammograms with corresponding compressed breast thickness information as described in this study. Fabrication of individual filters for a functional system could be accomplished with either a computerized milling machine or stereolithography. Plastics doped with metals such as aluminum and copper might be employed as the filter material in either case to reduce the required filter thickness. The filters would be automatically positioned by a microprocessor controlled stage that translates and rotates the appropriate filter to a location such that the projected filter exposure profile matches the compressed breast border derived from the TV camera image. The filter positioner would be located close to the $\mathrm{x}$-ray tube to minimize $\mathrm{x}$-ray scatter to the breast and minimize artifact production. The individual filters could be placed in the positioner manually, or an automated filter wheel could be developed. Lastly, the entire filter selection/positioning process should take place in only a few seconds to minimize patient discomfort from any additional time the breast must remain compressed. 

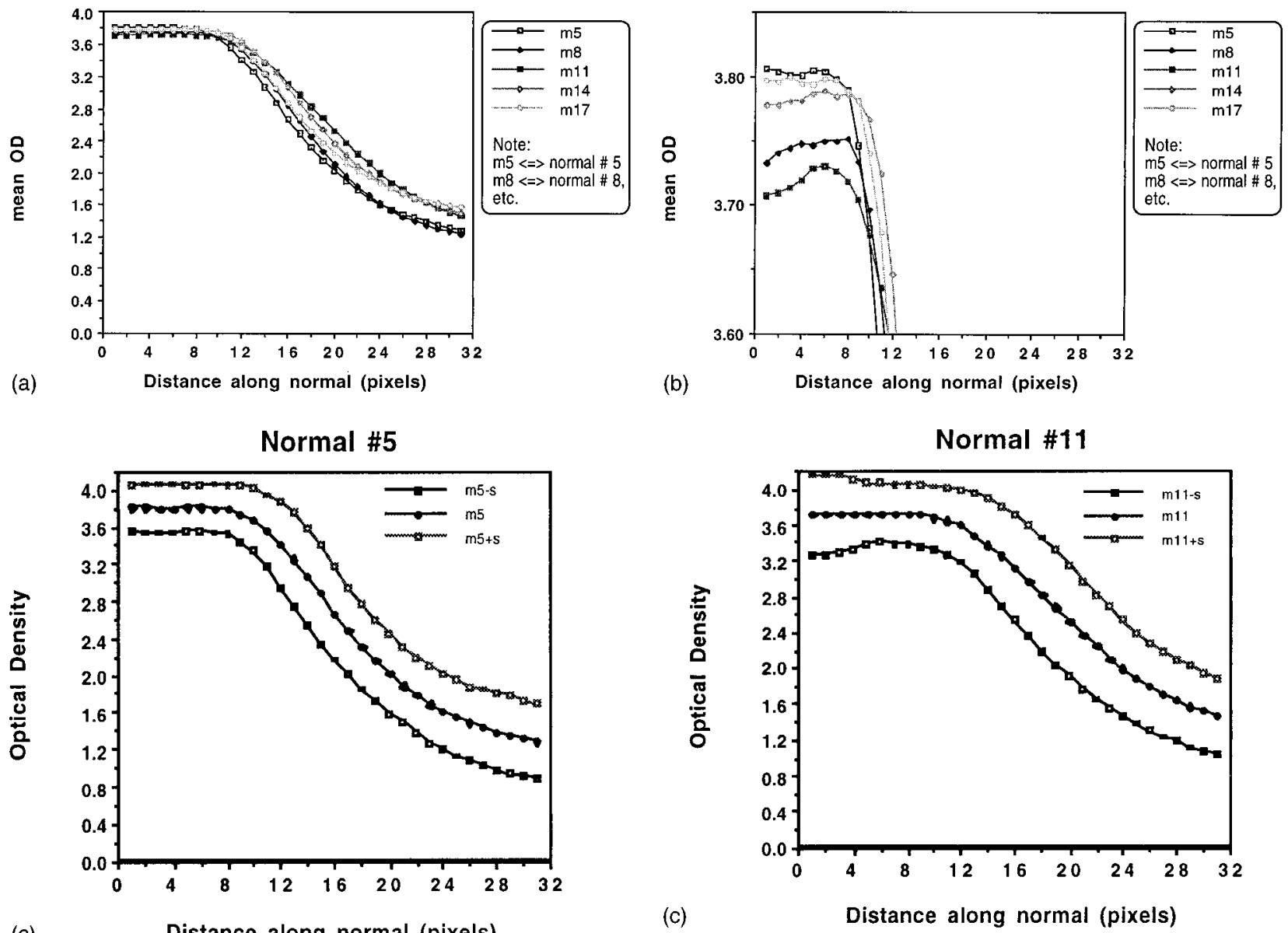

(c)

Distance along normal (pixels)

(c)

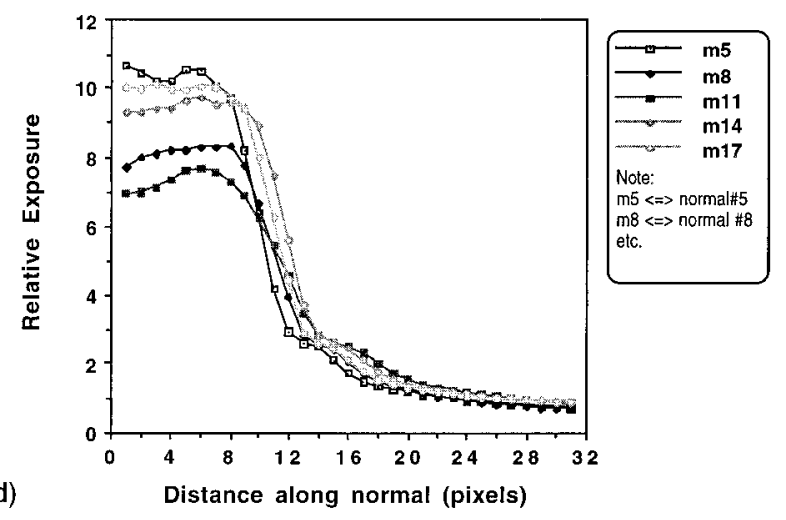

(c)

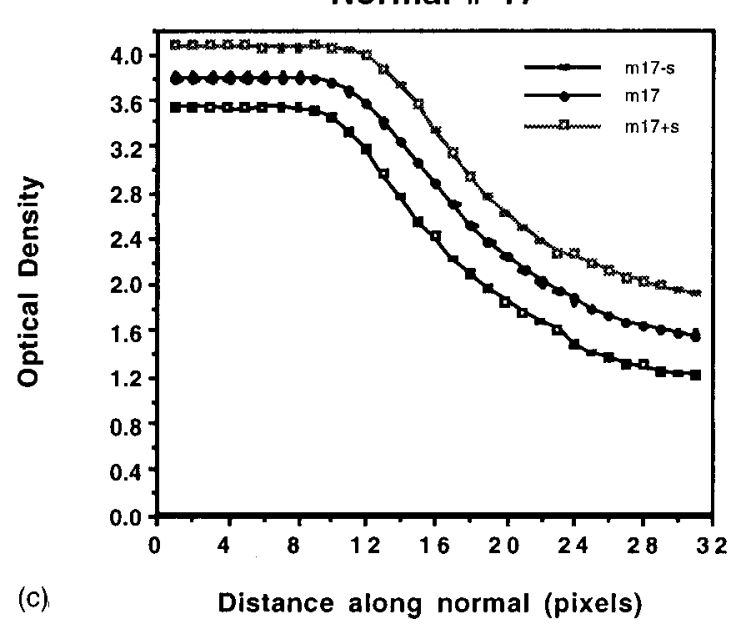

(d)

FIG. 10. (a) Mean optical density as a function of position along normals to the filter when the filter is aligned with the automatically detected borders in mammograms classified to belong to the filter shape. For the particular case shown, 231 CC-view borders were classified to match the filter. Pixel \#11 along each normal corresponds with the filter edge. Pixels less than 11 are outside the breast, and those greater than 11 are inside the breast. Normal \#11 is the middle normal (for a symmetric breast, it is closest to the nipple position). (b) Magnified view showing the details of the high optical density region in plot (a). (c) Mean optical density $+/-1$ standard deviation for selected normals. (d) Mean exposures corresponding to the optical densities in (a).

\section{ACKNOWLEDGMENT}

This work was supported in part by Grant No. DAMD 17-94-J-4292 from the USAMRMC.

${ }^{a}$ Corresponding author: Mitchell M. Goodsitt, Ph.D., University of Michigan Hospitals, Department of Radiology, Room B1F510C, 1500 E. Medi- cal Center Drive, Ann Arbor, MI 48109-0030. Electronic-mail: goodsitt@umich.edu

${ }^{b)}$ Present address: Vanstar Corp., 201 Hanfen Ct. Suite 119, Wood Dale, IL 60191.

${ }^{c}$ Present address: Industrial Electronics Lab, GE Corporate R\&D, Schenectady, NY 12301

${ }^{d)}$ Present address: Health Physics Office, Walter Reed Army Medical Cen- 
ter, Building 41, Rm. 38, 6825 16th St. NW, Washington DC 20307-5001.

${ }^{1}$ E. A. Sickles, "Mammographic features of "early" breast cancer,' Am. J. Roentgenol. 143, 461-464 (1984).

${ }^{2}$ E. A. Sickles, "Mammographic features of 300 consecutive nonpalpable breast cancers,' Am. J. Roentgenol. 146, 661-663 (1986).

${ }^{3}$ W. W. Logan and J. A. Janus, 'Screen/film mammography,', in Breast Cancer Detection: Mammography and Other Methods in Breast Imaging, 2nd ed., edited by L. W. Bassett and R. H. Gold (Grune \& Stratton, New York, 1987)

${ }^{4}$ R. M. Nishikawa, G. E. Mawdsley, A. Fenster, and M. J. Yaffe, 'Scanned-projection digital mammography,' Med. Phys. 14, 717-727 (1987).

${ }^{5}$ R. M. Nishikawa and M. J. Yaffe, "An investigation of digital mammographic imaging,' Proc. SPIE 419, 192-200 (1983).

${ }^{6} \mathrm{P}$. C. Bunch, K. E. Huff, and R. Van Metter, "Analysis of the detective quantum efficiency of a radiographic screen/film system,' J. Opt. Soc. Am. A 4, 902-909 (1987).

${ }^{7}$ H. R. Blackwell, "Contrast thresholds of the human eye,' J. Opt. Soc. Am. 36, 624-643 (1946).

${ }^{8}$ B. Baxter, H. Ravinda, and R. A. Normann, "Changes in lesion detectability caused by light adaptation in retinal photo-receptors,' Invest. Radiol. 17, 394-401 (1982).

${ }^{9}$ H. L. Snyder, "'Chapter 3: The Visual System: Capabilities and Limitations,', in Flat-Panel Display and CRTs, edited by L. E. Tannas, Jr. (Van Nostrand Reinhold, New York, 1985).

${ }^{10}$ L. D'Agincourt, "Technique is everything when breast is dense," Diagnostic Imaging, Sept., 57-61 (1993).
${ }^{11}$ K. L. Lam and H.-P. Chan, "Development of x-ray beam equalization technique in mammography," Radiology 169(P), 338 (1988).

${ }^{12}$ K. L. Lam and H.-P. Chan, "Exposure equalization techniques in mammography,', Invest. Radiol. 24, 154-157 (1989).

${ }^{13}$ K. L. Lam and H.-P. Chan, "Effects of X-ray beam equalization on mammographic imaging," Med. Phys. 17, 242-249 (1990).

${ }^{14}$ G. Panayiotakis, H. Likaki, Z. Kolitsi, and J. Dimopoulos, “An anatomical filter for exposure equalization in mammography,' Eur. J. Radiol. 15, 15-17 (1992).

${ }^{15}$ J. M. Sabol, I. C. Soutar, and D. B. Plewes, "Mammographic scanning equalization radiography,' Med. Phys. 20, 1505-1515 (1993).

${ }^{16}$ J. W. Oestmann, B. Stoel, H. Schrijvershof, J. Vrooman, and L. J. Schultze Kool, "Scanning equalization mammography: Preliminary evaluation,' Radiographics 14, 123-128 (1994).

${ }^{17}$ J. M. Sabol, I. C. Soutar, and D. B. Plewes, "Practical application of a scan-rotate equalization geometry to mammography,' Med. Phys. 23, 1987-1996 (1996).

${ }^{18}$ A. R. Morton, H. P. Chan, and M. M. Goodsitt, "Automated modelguided breast segmentation algorithm," Med. Phys. 23, 1107-1108 (1996).

${ }^{19}$ M. M. Goodsitt, H.-P. Chan, B. Liu, S. Guru, and R. Morton, "Compressed breast shape classification for the design of mammography equalization filters,', Med. Phys. 23, 1108 (1996).

${ }^{20}$ M. R. Andenberg, Cluster Analysis for Applications (Academic, New York, 1973). 